\title{
A role for steroid sulphatase in intracrine regulation of endometrial decidualisation
}

\author{
Douglas A Gibson', Paul A Foster², Ioannis Simitsidellis', Hilary O D Critchley³, Olympia Kelepouri', \\ Frances Collins ${ }^{1}$ and Philippa T K Saunders ${ }^{1}$
}

1MRC Centre for Inflammation Research, The University of Edinburgh, QMRI, Edinburgh, UK 2Institute of Metabolism \& Systems Research, University of Birmingham, Birmingham, UK. ${ }^{3}$ MRC Centre for Reproductive Health, The University of Edinburgh, QMRI, Edinburgh, UK

Correspondence should be addressed to D A Gibson: d.a.gibson@ed.ac.uk

This paper is part of a thematic section on Sulfation Pathways. The guest editors for this section were Jonathan Wolf Mueller and Paul Foster.

\begin{abstract}
In women, establishment of pregnancy is dependent upon 'fine-tuning' of the endometrial microenvironment, which is mediated by terminal differentiation (decidualisation) of endometrial stromal fibroblasts (ESFs). We have demonstrated that intracrine steroid metabolism plays a key role in regulating decidualisation and is essential for timedependent expression of key factors required for endometrial receptivity. The primary aim of the current study was to determine whether sulphated steroids can act as precursors to bioactive sex steroids during decidualisation. We used primary human ESF and a robust in vitro model of decidualisation to assess the expression of genes associated with sulphation, desulphation and transport of sulphated steroids in human ESF as well as the impact of the steroid sulphatase (STS) inhibitor STX64 (Irosustat). We found evidence for an increase in both expression and activity of STS in response to a decidualisation stimulus with abrogation of oestrone biosynthesis and decreased secretion of the decidualisation marker IGFBP1 in the presence of STX64. These results provide novel insight into the contribution of STS to the intracrine regulation of decidualisation.
\end{abstract}

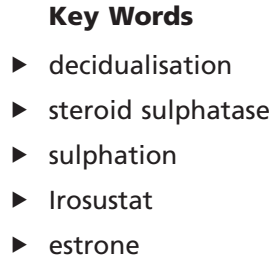

Journal of Molecular Endocrinology (2018) 61, M57-M65

\section{Introduction}

Decidualisation is a fundamental process of endometrial remodelling that is required for the establishment of pregnancy. It is associated with unique time-dependent transcriptomic and proteomic changes (reviewed in Gellersen \& Brosens 2014), which are reported to be disordered in women with recurrent implantation failure (Ruiz-Alonso et al. 2013, Koot et al. 2016). Whilst the post-ovulatory rise in progesterone acts as an endocrine signal to stimulate decidualisation of oestrogen-primed human endometrial stromal fibroblast (hESF) (reviewed in Gellersen \& Brosens 2014), we have demonstrated an important role for local (intracrine) steroid metabolism in fine-tuning the cellular differentiation of hESFs (Gibson et al. 2016b). Importantly, we have established that expression of CYP19A1 (aromatase, the key enzyme required for conversion of androgens to estrogens) as well as $A K R 1 C 3$ and SRD5A1 (enzymes that convert precursor androgens into testosterone and dihydrotestosterone (DHT), respectively) are altered in a time-dependent manner (Gibson et al. 2013, 2016a). Expression of these

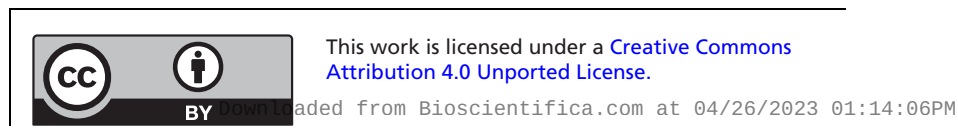


enzymes results in increased biosynthesis of potent steroid receptor agonists (E2, testosterone, DHT) that in turn regulate the expression of genes important for receptivity and immune-cell-mediated vascular remodelling (Gibson et al. 2013, 2015, 2016a).

Bioavailability of sulphated steroids can affect intratissue concentrations of oestrogens and androgens, which may play a major role in regulating the function of both normal and malignant tissues (Mueller et al. 2015). Hydrolysis of sulphated precursors into biologically active steroids requires the enzyme steroid sulphatase (STS) (Fournier \& Poirier 2009). STS primarily converts oestrone sulphate $\left(\mathrm{E}_{1} \mathrm{~S}\right)$ to oestrone (E1) and is expressed in many tissues, albeit at low levels (Miki et al. 2002, Suzuki et al. 2003). In addition to oestrogen-forming activities, STS also has the capacity to hydrolyse DHEAS to DHEA, which may also act as a precursor for the formation of oestrogens and androgens within target tissues (Purohit et al. 2011). The actions of STS are countered by sulphotransferases that promote inactivation and metabolism of steroids following conjugation of a sulphate moiety. Sulphotransferases are a diverse gene family and the isozymes SULT1A1, SULT1E1, SULT2A1 and SULT2B1 have been associated with sulphation of steroids (Mueller et al. 2015). SULT1E1 primarily catalyses the sulphation of oestrogens, although SULT1A1 is also reported to have this action (Gamage et al. 2005). Sulphation requires the co-substrate PAPS (adenosine 3 '-phosphate 5 '-phosphosulfate) that provides the universal sulphate donor compound for all sulphotransferase reactions. PAPS is synthesised via one of two PAPS synthase isoforms PAPSS1 and PAPSS2 (Schroder et al. 2012). Uptake and excretion of sulphated steroids from cells is regulated by membrane transporters which are reported to be expressed in endometrial and ovarian cancer cells and tissues (Mueller et al. 2015, Rizner et al. 2017). To date, few studies have examined the expression of STS, sulphotransferases, PAPSS or membrane transporters in endometrial tissues.

STS immunoexpression has been detected in both stromal and epithelial cells in the endometrium across the menstrual cycle (Dassen et al. 2007). In a study using 12 endometrial cancer samples and adjacent endometrium, expression of both STS and SULT1E1 mRNAs were higher in the normal endometrium than in the malignant cells (Smuc et al. 2006). Notably, in both benign and normal endometrial tissues, concentrations of mRNAs for STS were higher than SULT1E1 (Smuc et al. 2006), which may favour an increase in the bioavailability of active steroid receptor agonists in the endometrium. Indeed, studies using STX64 (Irosustat), an irreversible inhibitor of STS (Day et al. 2009), suggest that STS can regulate formation of oestradiol (E2) in the uterus (Colette et al. 2011). STS inhibitors are also reported to decrease the oestrogenic growth of hormonedependent tissues, including endometrial cancer tissues (Foster et al. 2008) and proliferation of human endometrial xenografts (Colette et al. 2011). Recently, Sinreih et al. extended their studies on endometrial cancer steroid intracrinology and concluded that $\mathrm{E} 2$ was formed from $\mathrm{E}_{1} \mathrm{~S}$ via the sulphatase pathway rather than via aromatase in endometrial cancer tissues (Sinreih et al. 2017). In contrast, previous studies in both human and mouse suggest intracrine regulation of the normal endometrium occurs via aromatase-dependent biosynthesis of oestrogens (Das et al. 2009, 2012, Gibson et al. 2013).

In thecurrentstudy, wesought tocomplementand extend our previous investigations by assessing the contribution of STS to intracrine regulation of decidualisation. We used an in vitro model of decidualisation to assess the expression of genes associated with sulphation, desulphation and transport of sulphated steroids in hESFs and assessed the impact of the STS inhibitor STX64 (Irosustat). Our results provide new insight into the mechanisms that contribute to generation of an oestrogen-rich microenvironment during the establishment of pregnancy.

\section{Materials and methods}

\section{Human studies}

Primary human endometrial tissue (proliferative phase, $n=9$ ) was obtained from women undergoing surgery for non-malignant gynaecological conditions. None of the women were receiving hormonal therapy or suffering from endometriosis. Primary hESFs were isolated from proliferative phase endometrium and cycle phase determined as reported previously (Bombail et al. 2010). Briefly, endometrial tissue was minced using scalpel blades, followed by DNAse/collagenase digest for $2 \mathrm{~h}$ at $37^{\circ} \mathrm{C}$. The tissue homogenate was then sequentially strained through $70 \mu \mathrm{m}$ and $40 \mu \mathrm{m}$ membrane filters to separate hESF from the glandular epithelium. Isolated hESFs were washed in warmed PBS and cultured in RPMI 1640, supplemented with $10 \%$ foetal calf serum (FCS) at $37^{\circ} \mathrm{C}$ in $5 \% \mathrm{CO}_{2}$ and maintained for a maximum of five passages. Forty-eight hours prior to experimentation, hESF culture media were changed to phenol red-free RPMI 1640 supplemented with 10\% charcoal-stripped FCS (CSFCS). Decidualisation was induced by addition of decidualisation (DEC) media (phenol red-free RPMI 1640, 2\% CSFCS, $0.1 \mathrm{mg} / \mathrm{mL}$ 8-Br-cAMP (Sigma, B5386), $1 \mu \mathrm{M}$ progesterone (Tocris, Abingdon, UK; Cat no. 2835)). Some cell cultures were

This work is licensed under a Creative Commons
Attribution 4.0 Unported License.


supplemented with the STS inhibitor Irosustat (STX64; $10 \mu \mathrm{M}$, Sigma S1950) for the duration of the culture period. Control cultures were incubated with phenol red-free RPMI 1640, 2\% CSFCS and equivalent volume of vehicle control (DMSO). $2 \times 10^{5} \mathrm{hESFs}$ were seeded per well of six-well plate, treatments were in duplicate and assessed in minimum of three individual patients for all treatments. For experiments assessing expression and activity of sulphation enzymes/transporters, cells from $n=6$ patients were assessed. For experiments assessing the impact of STX64, cells from $n=3$ patients were used. Each sample was assayed in duplicate and average values were analysed. To assess the time-dependent accumulation of secreted products, treatments were maintained for the duration of each time point. hESFs were treated for $24 \mathrm{~h}$ (1 day), $48 \mathrm{~h}$ (2 days), 4 days or 8 days as indicated; cells were treated in parallel with dedicated samples for each time point and patient. The expression of genes associated with sulphation, desulphation and transport of sulphated steroids was assessed by RT-qPCR.

\section{Assessment of mRNA}

Isolation of mRNAs, preparation of cDNAs and analysis by RT-qPCR was performed according to standard protocols (Bombail et al. 2010); samples were analysed by the comparative $\Delta \Delta \mathrm{Ct}$ method with $C Y C$ (cyclophilin) as an internal control. Primers/probes are given in Supplementary Table 1 (see section on supplementary data given at the end of this article).

\section{ELISA}

Insulin-like growth factor-binding protein 1 (IGFBP1), E1 and $\mathrm{E} 2$ in culture supernatants were determined by ELISA as described previously (Gibson et al. 2013, 2016a). E1 and E2 were not detected in control supernatants (not shown). Antibody cross-reactivity for E1 and E2 ELISA was $<5 \%$ for other steroids (Supplementary Tables 2 and 3).

\section{Measurement of steroid sulfatase activity}

STS activity was determined in cell lysates as described previously (Purohit et al. 1997). Briefly, cells were lysed in RIPA buffer and protein concentration measured by BCA assay. Hundred micrograms of protein were incubated for $4 \mathrm{~h}$ with PBS containing [6,7-3 $\mathrm{H}] \mathrm{E}_{1} \mathrm{~S}\left(4 \times 10^{5} \mathrm{dpm}\right)$ adjusted to a final concentration of $20 \mu \mathrm{M}$ with unlabelled $\mathrm{E}_{1} \mathrm{~S}$. $\left[4-{ }^{-14} \mathrm{C}\right] \mathrm{E} 1\left(1 \times 10^{4} \mathrm{dpm}\right)$ was used to monitor procedural losses. E1 was separated from $\mathrm{E}_{1} \mathrm{~S}$ by toluene partition and ${ }^{3} \mathrm{H}$ and ${ }^{14} \mathrm{C}$ radioactivity was measured by liquid scintillation spectrometry. Results were expressed as E1 formed $\mathrm{pmol} / \mathrm{h} / \mathrm{mg}$ protein.

\section{Statistics}

Statistical analysis was performed using GraphPad prism. Two-way ANOVA was used to determine the significance between treatments in grouped data; interaction between time and treatment was assessed, Sidak's multiple comparisons test was used to assess the differences between treatments for individual time points. Non-parametric testing was utilised where sample sizes were insufficient to confirm normality of data distribution; Mann-Whitney test was used to assess differences between treatments at each time point for RT-qPCR data. Criterion for significance was $P<0.05$. All data are presented as mean \pm s.e.m.

\section{Study approval}

Written informed consent was obtained from all subjects prior to surgery; ethical approval was granted by the Lothian Research Ethics Committee (LREC/07/S1103/29 and LREC 10/S1402/59). Methods were carried out in accordance with NHS Lothian Tissue Governance guidelines. Studies using these cells have previously been reported in (Gibson et al. 2018).

\section{Results}

\section{Expression of sulphation and desulphation enzymes} during decidualisation of human ESF

We assessed expression of STS as well as members of the sulphotransferase gene family in cells recovered 1-8 days after incubation with control (VC) or DEC culture media (Figs 1 and 2). Expression of STS was increased at all time points in hESF stimulated with DEC; results reached statistical significance in samples recovered on Day 1 (Fig. $1 \mathrm{~A} ; n=6 ; P<0.0001$ ), 2 (Fig. $1 \mathrm{~B} ; n=6 ; P<0.0001$ ) and 4 (Fig. $1 \mathrm{C} ; n=6 ; P<0.01$ ). To complement these findings, STS activity was assessed in cell lysates and was significantly increased in lysates from hESF treated with DEC media compared to VC after 4 days of treatment (Fig. 1E, $n=6$; $P<0.05)$.

To determine whether E1 and E2 formed by decidual cells (Gibson et al. 2013) might also be subject to inactivation, we also assessed expression of sulphotransferases in the same samples. In these experiments, expression of SULT1E1 and SULT2A1 mRNAs 


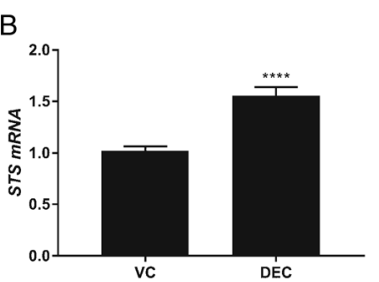

A

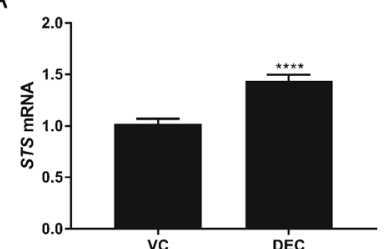

C

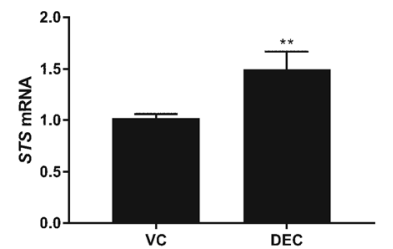

D
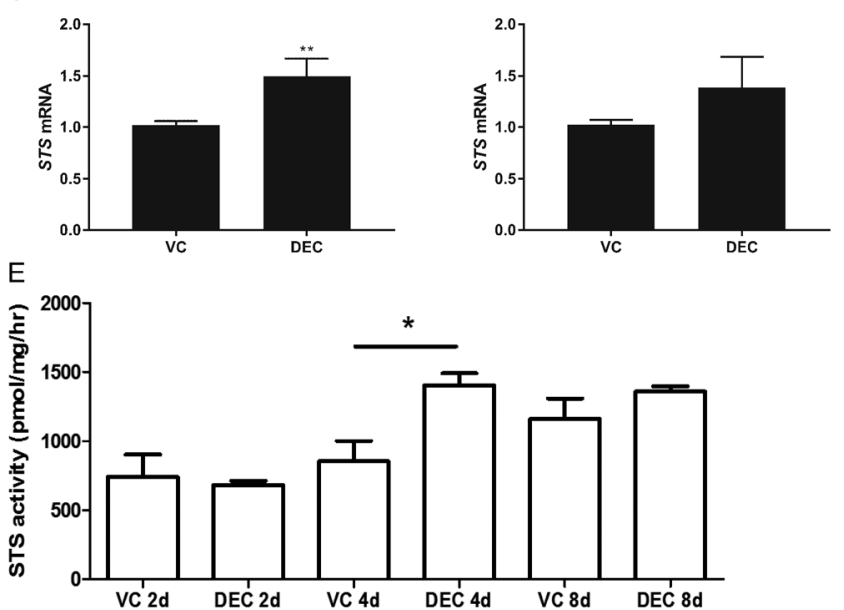

Figure 1

Expression and activity of STS during decidualisation. HESFs were treated with either VC or DEC for 1-8 days as indicated and mRNAs encoding STS were assessed by RT-qPCR. STS mRNA was significantly increased in hESF treated with decidualisation media for 1,2 and 4 days compared to VC but not different at the 8-day time point (A, B, C and D; $N=6$ patients, duplicate treatments; Mann-Whitney test.). STS activity was assessed in hESF (E) and was increased in cells treated with DEC compared to VC after 4 days $\left(P<0.05 ; n=6\right.$ patients, one-way ANOVA). ${ }^{*} P<0.05 ; * * P<0.01$; $* * * * P<0.0001$. DEC, decidualisation media; HESF, human endometrial stromal fibroblasts; STS, steroid sulphatase; VC, vehicle control.

were not detected (not shown). In contrast, mRNAs encoded by SULT1A1 and SULT2B1a were present (Fig. 2A and B). SULT1A1 mRNAs were significantly increased in hESF stimulated with DEC media compared to VC after 1 $(n=6 ; P<0.01), 2(n=6 ; P<0.001)$ and 8 days $(n=6 ; P<0.05)$ of culture. SULT2B1a mRNAs were significantly increased on days $1(n=6 ; P<0.0001)$ and $2(n=6 ; P<0.01)$ of culture, however, by day 8 , this was reversed with a significant decrease detected in DEC compared to VC-treated hESF $(n=6 ; P<0.05)$.

\section{Expression of PAPSS isozymes during decidualisation of hESF}

To complement and extend the studies on sulphotransferase enzymes, we also assessed expression of PAPSS isozymes PAPSS1 and PAPSS2. Expression of mRNAs encoded by PAPSS1 (Fig. 3A) was increased in DEC-treated hESF compared to controls on days $1(n=6 ; P<0.05)$ and 8 ( $n=6 ; P<0.01)$, whereas PAPSS2 mRNA concentrations were only higher on day $1(n=6 ; P<0.01)$ and unchanged at other time points (Fig. 3B).

\section{Expression of ATP-binding cassette transporters during decidualisation of human ESF}

We assessed expression of cellular transporters ABCC1 and ABCC4, which are associated with efflux of sulphated steroids. Expression of mRNAs encoding ABCC1 was increased in a time-dependent manner in decidualised hESF (Fig. 4A). ABCC1 mRNA expression was significantly increased in DEC compared to controls at each time point; $1(n=6 ; P<0.0001), 2(n=6 ; P<0.0001)$ and $4(n=6$; $P<0.01)$ days, with the greatest increase in expression detected after 8 days $(n=6 ; P<0.0001)$. In contrast, ABCC4 mRNA expression was significantly decreased in hESF treated with DEC compared to controls at 2 $(n=6 ; P<0.01), 4(n=6 ; P<0.0001)$ and $8(n=6 ; P<0.01)$ days (Fig. 4B). Expression of organic anion-transporting
A $1 d$

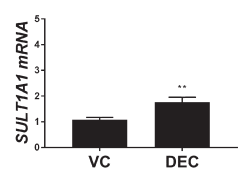

B

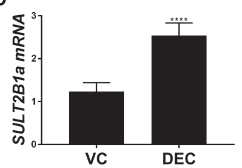

$2 d$
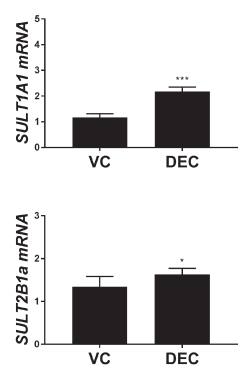

$4 d$
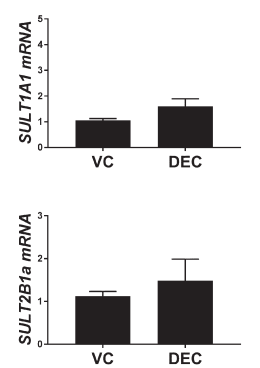

http://jme.endocrinology-journals.org https://doi.org/10.1530/JME-18-0037

C) 2018 The authors Published by Bioscientifica Ltd. Printed in Great Britain

Figure 2

Expression of sulphation enzymes during decidualisation. HESFs were treated with either VC or DEC for 1-8 days as indicated and mRNAs encoding SULT2B1 transcript variant 1 (SULT2B1a) and SULT1A1 were assessed by RT-qPCR. (A) SULT1A1 mRNA was significantly increased at 1, 2 and 8 days in hESF treated with DEC compared to VC. (B) SULT2B1a mRNA was significantly increased after 1- and 2-day treatment with DEC but by 8 days was significantly decreased compared to VC treatment. Expression of SULT1E1 and SULT2A1 was not detected (not shown). $n=6$ patients, duplicate treatments. Mann-Whitney test. $* P<0.05 ; * * P<0.01 ; * * * P<0.001$;

$* * * * P<0.0001$. DEC, decidualisation media; HESF, human endometrial stromal fibroblasts; VC, vehicle control.

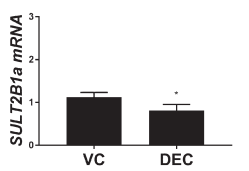

This work is licensed under a Creative Common Attribution 4.0 Unported License. 
A

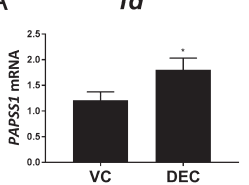

B

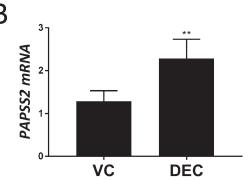

$2 d$
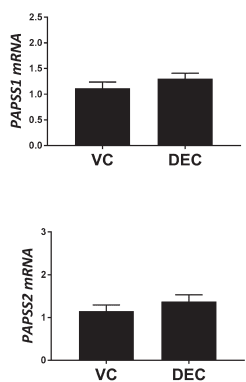

$4 d$
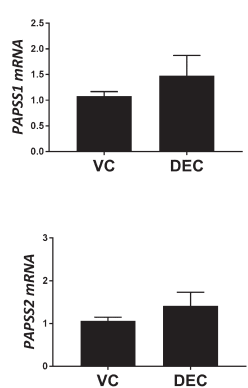

polypeptide transporters (SLC gene family; SLCO1A2, SLCO1B1, SLCO1B3 and SLCO2B1), which mediate influx of sulphated steroids were not detected in either control or decidualised hESF (not shown).

In light of these results and as a complement to our previous studies in which we demonstrated that both E1 and E2 are secreted into culture media during our decidualisation protocol (as determined by ELISA (Gibson et al. 2013)), we used sensitive LC-MS to assess the concentrations of $E_{1} S$ or $\mathrm{E}_{2} \mathrm{~S}$ in conditioned media from hESF, however, neither steroid was detected in either the control or DEC samples (not shown; LLOD for $\mathrm{E}_{1} \mathrm{~S}$ and $\mathrm{E}_{2} \mathrm{~S}=0.5 \mathrm{ng} / \mathrm{mL}$ ).

\section{Irosustat (STX64) disrupts bioavailability of oestrogens and alters decidualisation responses}

We investigated the potential importance of STS activity during decidualisation of hESF by assessing the impact of the selective, irreversible STS inhibitor Irosustat (STX64). hESFs were stimulated with DEC media or co-incubated with STX64 (DEC STX) for 1, 2, 4 or 8 days. Incubation with STX64 was associated with altered production of

\section{Figure 3}

Expression of PAPSS isozymes during decidualisation. HESF were treated with either VC or DEC for 1-8 days as indicated and mRNAs encoding PAPSS1 and PAPSS2 were assessed by RT-qPCR. (A) PAPPS1 mRNA was significantly increased at 1 and 8 days in hESF treated with DEC compared to VC while PAPSS2 mRNA (B) was increased only after 1 day. $n=6$ patients, duplicate treatments. Mann-Whitney test. ${ }^{*} P<0.05 ;{ }^{*} P<0.01$. DEC, decidualisation media; HESF, human endometrial stromal fibroblasts; PAPSS, adenosine 3'-phosphate 5'-phosphosulfate synthase; VC, vehicle control.

oestrogens from hESF and mean concentrations of secreted E1 were decreased at each time point in hESF treated with DEC STX compared to DEC alone (Fig. 5A). The impact of STX on E1 secretion was time-dependent with the greatest reduction detected after 1 day (32\% decrease in E1; $n=3$ patients, $P<0.05)$ but at later time points, there was no significant difference between hESF treated with DEC and DEC STX. In contrast to E1, concentrations of secreted E2 were not altered between hESF treated with either DEC alone or DEC STX (Supplementary Fig. 1). We next assessed if altered bioavailability of oestrogens affected decidualisation of hESF. Notably, STX64 altered secretion of the decidualisation marker IGFBP1; with concentrations reduced at each time point and significantly decreased after 1 day in hESF treated with DEC STX compared to DEC alone (Fig. 5B, $n=3$ patients, $P<0.05$ ).

\section{Discussion}

Oestrogens within tissues can be derived from two pathways; de novo synthesis, which requires aromatase, and activation of circulating sulphated steroids which requires

A

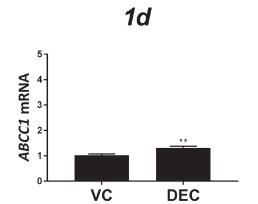

B

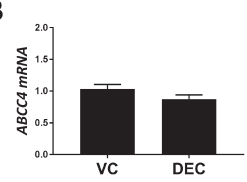

$2 d$
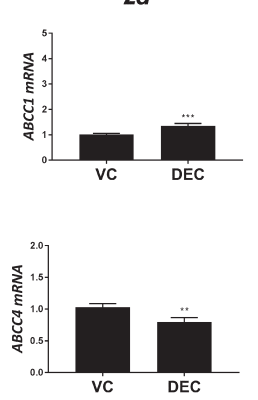

$4 d$
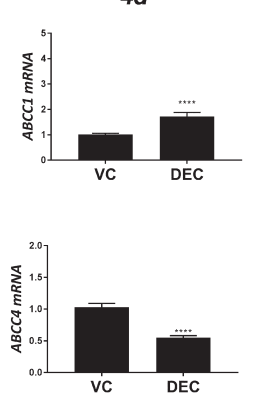

http://jme.endocrinology-journals.org https://doi.org/10.1530/JME-18-0037

(C) 2018 The authors Published by Bioscientifica Ltd. Printed in Great Britain

\section{Figure 4}

Expression of ATP-binding cassette transporters during decidualisation. HESFs were treated with either VC or DEC for 1-8 days as indicated and mRNAs encoding $A B C C 1$ and $A B C C 4$ were assessed by RT-qPCR. (A) ABCC1 mRNA increased in a time-dependent manner and was significantly increased in hESF treated with decidualisation media for 1, 2, 4 and 8 days compared to VC. (B) $A B C C 4$ mRNA decreased in a time-dependent manner and was significantly decreased after 2, 4 and 8 days of treatment with DEC compared to VC. Expression of mRNAs encoding the organic anion transporters SLCO1A2, SLCO1B1, SLCO1B3 and SLCO2B1 decidualisation media; HESF, human endometrial SULT1E1 were not detected. $n=6$ patients, duplicate treatments. Mann-Whitney test. $* * P<0.01 ; * * * P<0.001 ; * * * * P<0.0001$. DEC, stromal fibroblasts; VC, vehicle control.

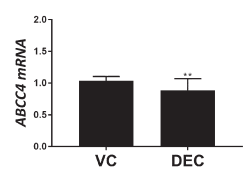

This work is licensed under a Creative Commons Attribution 4.0 Unported License. 
A

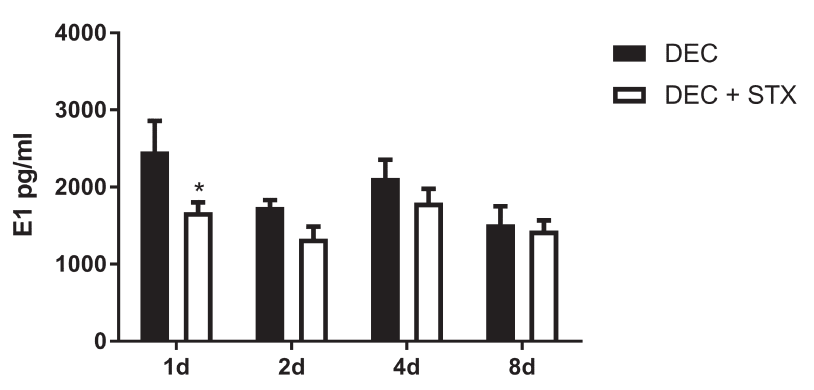

$\mathrm{B}$

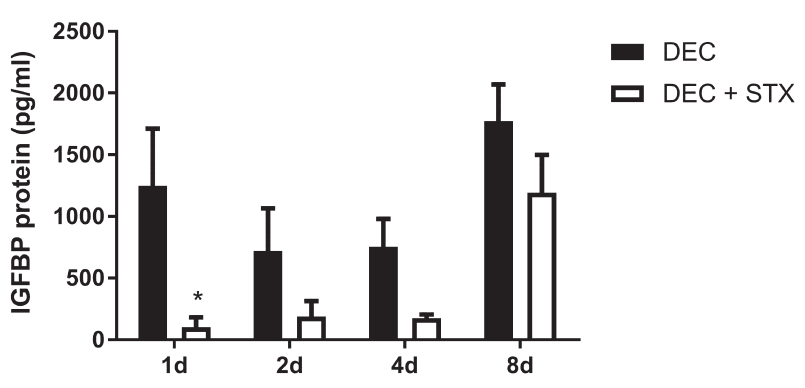

Figure 5

Irosustat (STX64) disrupts oestrogen bioavailability and alters decidualisation responses. The impact of the potent irreversible STS inhibitor STX64 (STX) on decidualisation of hESF was investigated following treatment for 1-8 days as indicated. (A) Secretion of E1 was significantly decreased after 1 day in hESF treated with DEC + STX compared to DEC alone $(P<0.05)$. Two-way ANOVA; global analysis time factor $P=0.0158$, treatment factor $P=0.0111$. Sidak's multiple comparisons test; treatment effect significantly different day $1 P<0.05$. (B) Concentrations of IGFBP1 tended to be lower at all time points in hESF treated with DEC+STX compared to DEC alone. STX significantly decreased secretion of the decidualisation marker IGFBP1 after 1 day of treatment $(P<0.05)$. Two-way ANOVA; global analysis time factor $P=0.0026$, treatment factor $P=0.0008$. Sidak's multiple comparisons test; treatment effect significantly different day $1 P<0.05$. E1 and IGFBP1 secretion was determined by ELISA. $n=3$ patients, duplicate treatments. ${ }^{*} P<0.05$. DEC, decidualisation media; E1, oestrone; HESF, human endometrial stromal fibroblasts; IGFBP1, insulin-like growth factorbinding protein-1.

STS (Simpson et al. 1994, Mueller et al. 2015). While de novo oestrogen synthesis via aromatase has emerged as a key steroidogenic process in the normal endometrium (Das et al. 2009, 2012, Gibson et al. 2013), activation of sulphated steroids via STS is reported to be a prominent mechanism of oestrogen activation in pathologies of the endometrium including endometrial cancer and endometriosis (Colette et al. 2011, Sinreih et al. 2017). To date, the literature supports that aromatase-dependent de novo synthesis of oestrogens is essential for intracrine regulation of endometrial function. Das et al. provided the first evidence that de novo synthesis of oestrogens was required for decidualisation (Das et al. 2009). Using a mouse model, they showed that following ovariectomy on day 5 of pregnancy, supplementation with progesterone was sufficient to maintain the decidualisation response as well as growth and development of implanted embryos, (Das et al. 2009). However, in the presence of the aromatase inhibitor letrozole, both decidualisation and implantation were impaired indicating that ovarian oestrogens were dispensable for decidualisation (Das et al. 2009). In further experiments using a mouse model of artificially induced decidualisation, they went on to show that factors required for stromal remodelling and neovascularisation were dependent on aromatase-dependent intrauterine de novo biosynthesis of oestrogens (Das et al. 2009, 2012). Our recent studies have extended these observations in mice and found evidence for complementary mechanisms in human endometrial stromal fibroblasts. We have shown that hESF have the capacity to utilise DHEA as a substrate and that hESF synthesise aromatisable androgens during decidualisation (Gibson et al. 2013, 2016a, 2018). We have demonstrated that decidualisation is characterized by an increase in the expression and activity of aromatase (CYP19A1) leading to local biosynthesis of both $\mathrm{E} 1$ and $\mathrm{E} 2$ within the microenvironment of the endometrial stroma (Gibson et al. 2013). We have also demonstrated that oestrogens regulate cellular cross-talk within the endometrium during the establishment of pregnancy by directly regulating immune cell function and promoting vascular remodelling (Gibson et al. 2015). Given that oestrogens play such an essential role in modulating the endometrial environment, in the present study, we sought to further examine the mechanisms that regulate the availability of oestrogens by assessing the contribution of STS to intracrine oestrogen bioavailability during decidualisation.

We speculated that in addition to the classic de novo biosynthesis pathway, oestrogens may also be synthesised via de-sulphation of $\mathrm{E}_{1} \mathrm{~S}$. Using a robust model of in vitro decidualisation and hESF, we detected increased expression and activity of STS. Notably, we found that the STS inhibitor STX64 (Irosustat) had a time-dependent impact on decidualisation and decreased secretion of IGFBP1 from days 1 to 4 of the time course. Decreased secretion of IGFBP1 was associated with concomitant decreases in E1 concentrations suggesting STS-dependent regulation of intracrine oestrogens occurs during decidualisation. Notably, the aromatase inhibitor letrozole is reported to completely inhibit uterine oestrogen production in ovariectomised mice (Das et al. 2009). However, in our previous study, we co-incubated hESF with the aromatase inhibitor letrozole during decidualisation, and this only reduced secretion of E1 and E2 by approximately 65\% (Gibson et al. 2013). In the current study, E1 synthesis was reduced by up to $30 \%$ during decidualisation consistent with both STS- and aromatase-dependent production of E1

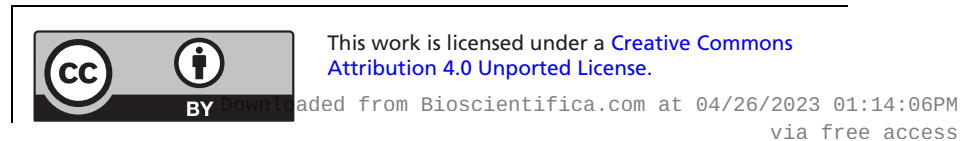


during decidualisation. Notably, the effect of STX64 on E1 concentrations was most pronounced at day 1 but absent by day 8 . This reflects our previous observations regarding the role of intracrine sex steroids during decidualisation, whereby modulation of local androgen action resulted in time-dependent changes in the expression of decidualisation and implantation-associated factors in the presence of the antiandrogen flutamide (Gibson et al. 2016a). Thus, if sulphated oestrogens are contributing to the 'oestrogen pool' during decidualisation, this effect may also be temporally regulated, with increased de-sulphation of steroid precursors during the early stages of decidualisation preceding aromatase-dependent synthesis of oestrogens during the latter stages of the differentiation process. Our results therefore suggest sulphation pathways contribute to regulation of decidualisation via rapid as well as gradual mechanisms. Taken together, our findings suggest bioavailability of intracrine oestrogens modulates initiation of stromal decidualisation and that tightly controlled regulation of intracrine steroids, via sulphation and export, is required as decidualisation progresses for appropriate paracrine signalling to immune and vascular endothelial cells within the tissue microenvironment during endometrial remodelling.

Notably, the most abundant oestrogen detected in the current analysis and in our previous study (Gibson et al. 2013) was E1. This was surprising as E1 is classically considered to be weak/inactive oestrogen. However, our results are consistent with Huhtinen et al. who performed intra-tissue profiling of human endometrial tissues using LC-MS. They reported increased concentrations of E1 in secretory phase endometrium compared to serum concentrations and that mean intrauterine concentrations of E1 are greater than E2 in the secretory phase (Huhtinen et al. 2012). Although the role of E2 in regulating establishment of pregnancy is well established, the predominance of $\mathrm{E} 1$ in the intrauterine environment during the secretory phase may suggest an independent role for E1 in regulating endometrial function. We have previously demonstrated that equimolar concentrations of E1 (10nM) can directly regulate increases in ER-dependent migration of uterine NK cells to a similar extent as E2 (Gibson et al. 2015) and in the current study, it was notable that reduction of E1 concentrations but not E2 by STX64 abrogated secretion of the decidualisation marker IGFBP1. Whether E1 acts as a direct agonist or by modulating intracrine metabolism in this context requires further investigation. However, the findings in the current study provide new evidence that availability of E1 may independently contribute to regulation of the endometrial microenvironment.

$$
\text { http://jme.endocrinology-journals.org }
$$

Sulphation of steroids is a primary route for metabolism of active oestrogens in healthy peripheral tissues. Previous studies have demonstrated that mRNA expression of the main oestrogen sulphating enzyme SULT1E1 is detected at all stages of the menstrual cycle in total endometrial tissue extracts (Dassen et al. 2007). In the current study, SULT1E1 was not detected in hESF, consistent with classic metabolism studies, which only detected formation of $\mathrm{E}_{1} \mathrm{~S}$ from isolated endometrial epithelial, but not stromal, cells following incubation with E2 (Liu \& Tseng 1979). We did detect mRNA expression of SULT1A1 which is reported to be expressed in the endometrium (Rubin et al. 1999) and also has oestrogen sulphating activity (Falany \& Falany 1996), albeit in the micromolar range. Notably, increased concentrations of sulphotransferases (SULT1A1, SULT2B1) were detected concurrent with increased expression of PAPSS isozymes; however, we could not detect any sulphated oestrogens in conditioned media from hESF. There are limited data on the expression of transmembrane transporters that mediate cellular influx and efflux of sulphated steroids in the endometrium. Nishimura and Naito assessed mRNA expression of 46 ABC transporters and 108 SLC transporters in a range of tissues including 3 human uterine samples (Nishimura \& Naito 2005). Notably, relative expression of mRNAs (ratio of target genes to PPIA housekeeping gene) encoding SLCO1A2, SLCO1B1 and $S L C O 2 B 1$ as well as $A B C C 1$ and $A B C C 4$ were reported in uterine samples; although expression of SLC isoforms was relatively low compared to other tissues (Nishimura $\&$ Naito 2005). In the current study, we could not detect expression of SLC isoforms in hESF, however, ABC transporters (ABCC1 and ABCC4) were detected and dynamically regulated consistent with a possible role in export of sulphated steroids during decidualisation. It is a limitation of the current study that only the contribution of stromal compartment was assessed. Given the reported expression and activity of SULT1E1 in endometrial epithelial cells (Liu \& Tseng 1979), further studies are needed to assess the contribution of epithelial cells and stromal-epithelial interactions in regulating oestrogen bioavailability within the endometrium. Our data support STS activity is prominent in the stromal compartment during decidualisation and additionally we found some evidence for time-dependent increases in expression of sulphotransferase enzymes. We did not detect any secretion of sulphated oestrogens in conditioned medium for hESF, which may suggest that any sulphated oestrogens formed during decidualisation are subject to direct hydrolysis by STS.

This work is licensed under a Creative Common Attribution 4.0 Unported License. 
In our study, we used primary human cells and a well-characterised model of in vitro decidualisation; however, it is conceivable that adaptive metabolism and alternative pathways may be more prominent in disease states such as endometriosis and endometrial cancer where increased expression of STS has been reported (Utsunomiya et al. 2004, Piccinato et al. 2016, Sinreih et al. 2017). It is notable that balanced availability of oestrogens is required to regulate establishment of pregnancy. Increasing or decreasing E2 outside the normal physiological range is detrimental to implantation in mice (Ma et al. 2003). Furthermore, supraphysiological levels of E2 and progesterone as a result of controlled ovarian hyperstimulation during in vitro fertilization treatment protocols is associated with low implantation rates, possibly as a result of an altered steroid milieu (Pellicer et al. 1996). 'Out of phase' endometrial remodelling is a common feature of implantation failure but whether dysregulation of endometrial intracrine metabolism occurs in sub/infertility requires further investigation. Notably, drugs that target steroid metabolism such as aromatase inhibitors, STS inhibitors, DASI (dual aromatase-STS inhibitors) and 17BHSD1 inhibitors may affect endometrial function, and these potential actions should be considered in future therapeutic applications of these drugs in reproductive-aged women.

\section{Conclusions}

In the current study, we assessed the expression of sulphation and desulphation enzymes, sulphate donors and transmembrane transporters in hESFs during a time course of in vitro decidualisation. We found that inhibition of STS activity disrupted bioavailability of oestrogens and inhibited decidualisation responses consistent with stromal utilisation of sulphated steroids as precursors to active hormones during decidualisation. Elucidation of the complex intracrine metabolism of steroids within the endometrium during decidualisation will be critical to understanding the relevance of these findings to reproductive health and disease. The results of the current study provide new insight into the contribution of sulphated steroids to the regulation of decidualisation and expand our understanding of intracrine regulation of the endometrium during the establishment of pregnancy.

\section{Supplementary data}

This is linked to the online version of the paper at https://doi.org/10.1530/ JME-18-0037.

$$
\begin{aligned}
& \text { http://jme.endocrinology-journals.org } \\
& \text { https://doi.org/10.1530/JME-18-0037 }
\end{aligned}
$$

Declaration of interest

The authors declare that there is no conflict of interest that could be perceived as prejudicing the impartiality of this review.

\section{Funding}

Studies were supported by MRC Programme Grant G1100356/1 (P T K S); MRC grant MR/J003611/1 (to H O D C).

\section{Author contribution statement}

Experimental design: D A G, P T K S, experimental procedures: D A G, P A F, I S, F C, O K, manuscript preparation: D A G, I S, P T K S.

\section{Acknowledgements}

The authors thank Prof. Alistair Williams for histopathology, research nurses Sharon McPherson and Catherine Murray for patient recruitment, Dr Alison Murray and Dr Moira Nicol for isolation of primary endometrial stromal cells. They are grateful to members of PTKS laboratory for technical support and helpful feedback.

\section{References}

Bombail V, Gibson DA, Collins F, MacPherson S, Critchley HO \& Saunders PT 2010 A role for the orphan nuclear receptor estrogenrelated receptor alpha in endometrial stromal cell decidualization and expression of genes implicated in energy metabolism. Journal of Clinical Endocrinology and Metabolism 95 E224-E228. (https://doi. org/10.1210/jc.2010-0154)

Colette S, Defrere S, Lousse JC, Van Langendonckt A, Gotteland JP, Loumaye E \& Donnez J 2011 Inhibition of steroid sulfatase decreases endometriosis in an in vivo murine model. Human Reproduction 26 1362-1370. (https://doi.org/10.1093/humrep/der079)

Das A, Mantena SR, Kannan A, Evans DB, Bagchi MK \& Bagchi IC 2009 De novo synthesis of estrogen in pregnant uterus is critical for stromal decidualization and angiogenesis. PNAS 106 12542-12547. (https://doi.org/10.1073/pnas.0901647106)

Das A, Li Q, Laws MJ, Kaya H, Bagchi MK \& Bagchi IC 2012 Estrogeninduced expression of Fos-related antigen 1 (FRA-1) regulates uterine stromal differentiation and remodeling. Journal of Biological Chemistry 287 19622-19630. (https://doi.org/10.1074/jbc.M111.297663)

Dassen H, Punyadeera C, Kamps R, Delvoux B, Van Langendonckt A, Donnez J, Husen B, Thole H, Dunselman G \& Groothuis P 2007 Estrogen metabolizing enzymes in endometrium and endometriosis. Human Reproduction 22 3148-3158. (https://doi.org/10.1093/humrep/ dem310)

Day JM, Purohit A, Tutill HJ, Foster PA, Woo LW, Potter BV \& Reed MJ 2009 The development of steroid sulfatase inhibitors for hormonedependent cancer therapy. Annals of the New York Academy of Sciences 1155 80-87. (https://doi.org/10.1111/j.1749-6632.2008.03677.x)

Falany JL \& Falany CN 1996 Expression of cytosolic sulfotransferases in normal mammary epithelial cells and breast cancer cell lines. Cancer Research 56 1551-1555.

Foster PA, Woo LW, Potter BV, Reed MJ \& Purohit A 2008 The use of steroid sulfatase inhibitors as a novel therapeutic strategy against hormone-dependent endometrial cancer. Endocrinology 149 4035-4042. (https://doi.org/10.1210/en.2008-0223)

Fournier MA \& Poirier D 2009 Estrogen formation in endometrial and cervix cancer cell lines: involvement of aromatase, steroid sulfatase and 17beta-hydroxysteroid dehydrogenases (types 1, 5, 7 and 12). Molecular and Cellular Endocrinology 301 142-145. (https://doi. org/10.1016/j.mce.2008.08.027)

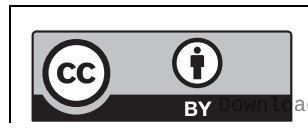

This work is licensed under a Creative Commons Attribution 4.0 Unported License. 
Gamage NU, Tsvetanov S, Duggleby RG, McManus ME \& Martin JL 2005 The structure of human SULT1A1 crystallized with estradiol. An insight into active site plasticity and substrate inhibition with multiring substrates. Journal of Biological Chemistry $28041482-41486$. (https://doi.org/10.1074/jbc.M508289200)

Gellersen B \& Brosens JJ 2014 Cyclic decidualization of the human endometrium in reproductive health and failure. Endocrine Reviews 35 851-905. (https://doi.org/10.1210/er.2014-1045)

Gibson DA, McInnes KJ, Critchley HO \& Saunders PT 2013 Endometrial intracrinology - generation of an estrogen-dominated microenvironment in the secretory phase of women. Journal of Clinical Endocrinology and Metabolism 98 E1802-E1806. (https://doi. org/10.1210/jc.2013-2140)

Gibson DA, Greaves E, Critchley HO \& Saunders PT 2015 Estrogendependent regulation of human uterine natural killer cells promotes vascular remodelling via secretion of CCL2. Human Reproduction 30 1290-1301. (https://doi.org/10.1093/humrep/dev067)

Gibson DA, Simitsidellis I, Cousins FL, Critchley HO \& Saunders PT $2016 a$ Intracrine androgens enhance decidualization and modulate expression of human endometrial receptivity genes. Scientitifc Reports 6 19970. (https://doi.org/10.1038/srep19970)

Gibson DA, Simitsidellis I \& Saunders PT $2016 b$ Regulation of androgen action during establishment of pregnancy. Journal of Molecular Endocrinology 57 R35-R47. (https://doi.org/10.1530/JME-16-0027)

Gibson DA, Simitsidellis I, Kelepouri O, Critchley HOD \& Saunders PTK 2018 Dehydroepiandrosterone enhances decidualization in women of advanced reproductive age. Fertility and Sterility 109 728.e722734.e722. (https://doi.org/10.1016/j.fertnstert.2017.12.024)

Huhtinen K, Desai R, Stahle M, Salminen A, Handelsman DJ, Perheentupa A \& Poutanen M 2012 Endometrial and endometriotic concentrations of estrone and estradiol are determined by local metabolism rather than circulating levels. Journal of Clinical Endocrinology and Metabolism 97 4228-4235. (https://doi. org/10.1210/jc.2012-1154)

Koot YE, van Hooff SR, Boomsma CM, van Leenen D, Groot Koerkamp MJ, Goddijn M, Eijkemans MJ, Fauser BC, Holstege FC \& Macklon NS 2016 An endometrial gene expression signature accurately predicts recurrent implantation failure after IVF. Scientific Reports 6 19411. (https://doi.org/10.1038/srep19411)

Liu HC \& Tseng L 1979 Estradiol metabolism in isolated human endometrial epithelial glands and stromal cells. Endocrinology 104 1674-1681. (https://doi.org/10.1210/endo-104-6-1674)

Ma WG, Song H, Das SK, Paria BC \& Dey SK 2003 Estrogen is a critical determinant that specifies the duration of the window of uterine receptivity for implantation. PNAS 100 2963-2968. (https://doi. org/10.1073/pnas.0530162100)

Miki Y, Nakata T, Suzuki T, Darnel AD, Moriya T, Kaneko C, Hidaka K, Shiotsu Y, Kusaka H \& Sasano H 2002 Systemic distribution of steroid sulfatase and estrogen sulfotransferase in human adult and fetal tissues. Journal of Clinical Endocrinology and Metabolism $\mathbf{8 7}$ 5760-5768. (https://doi.org/10.1210/jc.2002-020670)

Mueller JW, Gilligan LC, Idkowiak J, Arlt W \& Foster PA 2015 The regulation of steroid action by sulfation and desulfation. Endocrine Reviews 36 526-563. (https://doi.org/10.1210/er.2015-1036)

Nishimura M \& Naito S 2005 Tissue-specific mRNA expression profiles of human ATP-binding cassette and solute carrier transporter superfamilies. Drug Metabolism and Pharmacokinetics 20 452-477. (https://doi.org/10.2133/dmpk.20.452)

Pellicer A, Valbuena D, Cano F, Remohi J \& Simon C 1996 Lower implantation rates in high responders: evidence for an altered endocrine milieu during the preimplantation period. Fertility and Sterility 65 1190-1195. (https://doi.org/10.1016/S00150282(16)58337-X)

Piccinato CA, Neme RM, Torres N, Sanches LR, Derogis P, Brudniewski HF, Rosa ESJC \& Ferriani RA 2016 Effects of steroid hormone on estrogen sulfotransferase and on steroid sulfatase expression in endometriosis tissue and stromal cells. Journal of Steroid Biochemistry and Molecular Biology 158 117-126. (https://doi. $\operatorname{org} / 10.1016 /$ j.jsbmb.2015.12.025)

Purohit A, Froome VA, Wang DY, Potter BV \& Reed MJ 1997 Measurement of oestrone sulphatase activity in white blood cells to monitor in vivo inhibition of steroid sulphatase activity by oestrone3-O-sulphamate. Journal of Steroid Biochemistry and Molecular Biology 62 45-51. (https://doi.org/10.1016/S0960-0760(97)00018-6)

Purohit A, Woo LW \& Potter BV 2011 Steroid sulfatase: a pivotal player in estrogen synthesis and metabolism. Molecular and Cellular Endocrinology 340 154-160. (https://doi.org/10.1016/j.mce.2011.06.012)

Rizner TL, Thalhammer T \& Ozvegy-Laczka C 2017 The importance of steroid uptake and intracrine action in endometrial and ovarian cancers. Frontiers in Pharmacology 8 346. (https://doi.org/10.3389/ fphar.2017.00346)

Rubin GL, Harrold AJ, Mills JA, Falany CN \& Coughtrie MW 1999 Regulation of sulphotransferase expression in the endometrium during the menstrual cycle, by oral contraceptives and during early pregnancy. Molecular Human Reproduction 5 995-1002. (https://doi. org/10.1093/molehr/5.11.995)

Ruiz-Alonso M, Blesa D, Diaz-Gimeno P, Gomez E, FernandezSanchez M, Carranza F, Carrera J, Vilella F, Pellicer A \& Simon C 2013 The endometrial receptivity array for diagnosis and personalized embryo transfer as a treatment for patients with repeated implantation failure. Fertility and Sterility 100 818-824. (https://doi.org/10.1016/j.fertnstert.2013.05.004)

Schroder E, Gebel L, Eremeev AA, Morgner J, Grum D, Knauer SK, Bayer P \& Mueller JW 2012 Human PAPS synthase isoforms are dynamically regulated enzymes with access to nucleus and cytoplasm. PLOS ONE 7 e29559. (https://doi.org/10.1371/journal. pone.0029559)

Simpson ER, Mahendroo MS, Means GD, Kilgore MW, Hinshelwood MM, Graham-Lorence S, Amarneh B, Ito Y, Fisher CR, Michael MD, et al. 1994 Aromatase cytochrome P450, the enzyme responsible for estrogen biosynthesis. Endocrine Reviews 15 342-355. (https://doi.org/10.1210/edrv-15-3-342)

Sinreih M, Knific T, Anko M, Hevir N, Vouk K, Jerin A, Frkovic Grazio S \& Rizner TL 2017 The significance of the sulfatase pathway for local estrogen formation in endometrial cancer. Frontiers in Pharmacology $\mathbf{8}$ 368. (https://doi.org/10.3389/fphar.2017.00368)

Smuc T, Rupreht R, Sinkovec J, Adamski J \& Rizner TL 2006 Expression analysis of estrogen-metabolizing enzymes in human endometrial cancer. Molecular and Cellular Endocrinology 248 114-117. (https:// doi.org/10.1016/j.mce.2005.10.013)

Suzuki T, Miki Y, Nakata T, Shiotsu Y, Akinaga S, Inoue K, Ishida T, Kimura M, Moriya T \& Sasano H 2003 Steroid sulfatase and estrogen sulfotransferase in normal human tissue and breast carcinoma. Journal of Steroid Biochemistry and Molecular Biology 86 449-454. (https://doi.org/10.1016/S0960-0760(03)00356-X)

Utsunomiya H, Ito K, Suzuki T, Kitamura T, Kaneko C, Nakata T, Niikura H, Okamura K, Yaegashi N \& Sasano H 2004 Steroid sulfatase and estrogen sulfotransferase in human endometrial carcinoma. Clinical Cancer Research 10 5850-5856. (https://doi. org/10.1158/1078-0432.CCR-04-0040)

Received in final form 24 April 2018

Accepted 2 May 2018

Accepted Preprint published online 2 May 2018 http://jme.endocrinology-journals.org https://doi.org/10.1530/JME-18-0037
(C) 2018 The authors Published by Bioscientifica Ltd. Printed in Great Britain

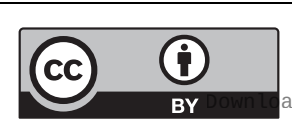

This work is licensed under a Creative Common Attribution 4.0 Unported License. ded from Bioscientifica.com at 04/26/2023 01:14:06PM 